\title{
O futuro dos cursos de direitos: entre a incerteza e a perplexidade
}

\author{
PALMEIRA, Lana Lisiêr de Lima ${ }^{1}$ \\ PRADO, Edna Cristina do ${ }^{2}$ \\ CORDEIRO, Carla Priscilla Barbosa Santos ${ }^{3}$
}

\section{Resumo}

Este artigo objetiva discutir a estrutura e organização dos cursos jurídicos sobre o prisma das diretrizes curriculares para o curso de Direito, inseridas na Resolução CNE/CES no 9/2004. A partir de um estudo histórico sobre o nascimento e formação dos cursos jurídicos no Brasil, pretende-se compreender a evolução do currículo jurídico ao longo dos anos. Em seguida, pretende-se analisar as atuais diretrizes vigentes para 0 ensino jurídico, compreendendo suas ideias centrais e seus objetivos. Por fim, pretendese analisar a proposta para as novas diretrizes curriculares para o curso de Direito, verificando-se de que forma as mudanças pretendidas poderão afetar a qualidade do ensino jurídico.

Ensino jurídico. diretrizes curriculares. Resolução CNE/CES no 9/2004.

\section{Resumen}

Este artículo objetiva discutir la estructura y organización de los cursos jurídicos sobre el prisma de las directrices curriculares para el curso de Derecho, insertado en la Resolución CNE/CES n 9/2004. A partir de un estudio histórico sobre el nacimiento y la formación de los cursos jurídicos en Brasil, se pretende comprender la evolución del currículo jurídico a lo largo de los años. A continuación, se pretende analizar las actuales directrices vigentes para la enseñanza del derecho, comprendiendo sus ideas centrales y objetivos. Por último, se pretende analizar la propuesta para las nuevas directrices curriculares para el curso de Derecho, verificando de que forma las modificaciones pretendidas afectarán la calidad de la enseñanza jurídica.

Enseñanza jurídica. Directrices curriculares. Resolución CNE/CES no 9/2004.

\footnotetext{
${ }^{1}$ Doutoranda em Educação pela UFAL, mestra em Educação pela mesma instituição e bacharela em Direito. Atua como docente e vice-diretora da Faculdade SEUNE. Advogada. Email: lanallpalmeira@outlook.com.

${ }^{2}$ Pós-doutorado pelo Instituto de Educação da Universidade de Lisboa; doutora em Educação pela UNESP, mestre em Educação pela PUC/SP, bacharel em Direito pela FMN, licenciada em Educação Física, Pedagogia, Letras e bacharel em Linguística pela USP, especialista em Psicologia, também pela USP, em Ecoturismo pela UFLA, em Tutoria em EaD pelo Senac/PR. Professora da Universidade Federal de Alagoas. Email: wiledna@uol.com.br

${ }^{3}$ Doutoranda em Educação, mestra em Direito e bacharela em Direito pela UFAL. Atualmente estuda Pedagogia, atua como docente universitária e pesquisadora da esfera da educação jurídica e do Direito. Email: cpbsc@outlook.com
} 


\section{Introdução}

Os primeiros cursos jurídicos surgiram em Portugal por volta de 1520, inaugurando o bacharelismo na seara jurídica. Alguns fatores foram fundamentais para a formação de um perfil determinado para o curso de Direito. Um deles foi a transição da Idade Média para a Moderna experimentada por Portugal à época, mas que manteve vivos valores do Antigo Regime na cultura portuguesa. Dentre esses valores, permaneceu a crença de que o curso de Direito estaria reservado aos nobres ou "enobrecidos".

Sob o prisma da história e cultura brasileira, muito foi absorvido deste processo quando da fundação dos primeiros cursos jurídicos no país. A formação do Brasil Colônia teve a presença marcante de bacharéis em Direito a representar a nobreza portuguesa, o que influenciou a construção da burocracia estatal que nascia no país. Desta maneira, a formação na seara jurídica sempre trouxe um determinado status social para aqueles que a possuíam, uma vez que viriam a operacionalizar o setor judiciário e vários cargos públicos.

Desta maneira, o ensino superior brasileiro foi inaugurado no país com a fundação das primeiras Academias de Direito: o primeiro em março de 1828, com sede em São Paulo, e o segundo em Olinda (que em seguida foi transferido para o Recife). Estes centros de ensino jurídico possuíam uma matriz curricular bastante conservadora, sendo marcados pelos interesses das elites dominantes à época.

Trata-se, de fato, de um curso que possui enorme tradição dentro do ensino superior brasileiro. Mesmo com essa historicidade que lhe é inerente, o fato é que os cursos de Direito atualmente experimentam uma grande crise em sua estrutura e organização. Práticas que marcaram os cursos de Direito, como o apego ao dogmatismo, ainda hoje se fazem presentes nos cursos jurídicos.

A atual formatação da matriz curricular dos cursos jurídicos estabelece três eixos de formação: fundamental, profissional e prática, com o objetivo de propiciar uma formação humanística e que permita ao estudante de Direito intervir de forma reflexiva e crítica na realidade social. Mesmo assim, várias deficiências são sentidas na esfera do ensino jurídico, o que tem levado a uma série de reflexões sobre a necessidade de mudança das atuais bases dos cursos jurídicos. (MURARO, 2010; PALMEIRA, 2011).

Assim, encontra-se em discussão uma proposta de novas diretrizes curriculares para o curso de Direito, com o objetivo de reorganizar a formatação dos atuais cursos jurídicos. A questão que se levanta é se tal proposta será positiva ou negativa aos cursos jurídicos, se propiciará a melhoria dos mesmos ou seu sucateamento.

Desta forma, este artigo objetiva discutir a organização e estrutura dos cursos jurídicos sob o prisma das suas diretrizes curriculares, analisando-se como a proposta em vigor vai alterar o ensino jurídico e a composição de sua matriz curricular. 


\section{0 surgimento dos cursos jurídicos}

O bacharelismo como modo de ser e de viver teve início em Portugal, precisamente em Coimbra, em pleno apogeu do absolutismo.

Os estudos jurídicos institucionalmente organizados começaram em Portugal, exatamente em 1290, por determinação de Dom Diniz, tendo funcionado em várias cidades lusitanas, até que a primeira Universidade portuguesa teve sua sede transferida para Coimbra, em definitivo, em 1537, por decisão de Dom João III, onde continuou a funcionar a formação dos bacharéis de Portugal e de suas colônias por vários séculos.

Durante parte desse período, a Europa atravessava a fase de transição entre o período medieval e a era moderna, que marcou profundamente a história do Direito como curso. Embora houvesse uma acentuada decadência da nobreza e da influência do mundo ibérico e, dentro dele, Portugal, conseguiram manter vivos, modernidade adentro, valores e estatutos do chamado Antigo Regime. Vale ressaltar, aqui, que a nobreza permaneceu muito presente na vida portuguesa até o século XIX sendo dividida em dois subtipos: a nobreza de espada, que representava a nobreza hereditária ou sanguínea e a nobreza togada ou outorgada, que correspondia à categoria de pessoas que conseguiam adquirir títulos e cargos, sendo também denominados enobrecidos.

É nesse intento de se tornar um nobre ou mesmo um enobrecido que surgiu a procura pelos cursos jurídicos, já que conforme destaca Saldanha (1998) a expressão bacharel traduz uma espécie de nobreza substitutiva, a nobreza togada, obtida dentro de uma sociedade hierárquica para aqueles que se intitulavam na universidade.

Assim,

Preparados para servirem ao sistema mantido pela nobreza e pela Igreja, na velha Europa, nos castelos e nos palácios, os bacharéis, depois de formados, recebiam nomeações imperiais. Durante algum tempo serviam nas proximidades dos reis e imperadores, como que fazendo uma espécie de estágio. Depois os bacharéis progrediam de acordo com os seus talentos e 0 grau de aprendizado, ou ainda pela combinação da sua personalidade, carisma, vocação, laços de família etc. Com o tempo os bacharéis passaram a formar um novo poder aristocrático. Envolvidos em suas sobrecasacas, becas de seda preta [...] o modelo de bacharelismo foi transposto para o Brasil no mesmo formato coimbrão que de resto é o mesmo forjado na Europa. (VENÂNCIO FILHO, 1982, p. 214).

No Brasil, tem-se o cenário do ensino superior brasileiro inaugurado pelos cursos jurídicos, os quais apresentavam toda uma tradição ancorada no valor simbólico da representação que se fazia e se faz em torno do que significa, 
no imaginário social, ser bacharel em Direito.

Como muito bem enfatiza Venâncio Filho (1982, p. 271), "a presença do bacharel em Direito é uma constante na vida brasileira. No início da colonização, as primeiras expedições portuguesas já encontraram em São Vicente o bacharel de Cananéia".

Araújo (2003, p. 207), por seu turno, em dizeres que confirmam bem a assertiva de Venâncio Filho, de fato, assevera que em 1531 "a esquadra de Martim Afonso de Souza, despachada com a missão de ocupação formal da nova colônia, encontrou o Bacharel vivendo pacificamente entre os índios".

Desse modo, seguindo as palavras de Venâncio Filho (1982, p. 271), pode-se dizer, metaforicamente, que "[...] atrás das pegadas das botas dos colonizadores estavam as sandálias dos padres e a beca do bacharel".

Dentro dessa vertente, tem-se que não é fato isolado no nosso contexto histórico a necessidade existente no período colonial brasileiro de pessoas com um grau de instrução mais elevado, pois a máquina estatal ia se tornando cada vez mais complexa, principalmente no setor judiciário, demandando assim uma formação mais vasta e formal.

Por isso, na primeira década da independência político-administrativa do Brasil, o país alcançou uma grande conquista: a Lei de 11 de agosto de 1827, sancionada por D. Pedro I, a primeira referente ao ensino superior pelo governo imperial, a qual foi o diploma fundador das primeiras escolas desse nível no país, que não por acaso, eram de ensino jurídico (PALMEIRA, 2011).

Assim, recebendo a nomenclatura de Academias de Direito, foram implantados os dois primeiros cursos no Brasil, o primeiro em março de 1828, com sede em São Paulo, instalado no Convento de São Francisco e o segundo localizado em Olinda, no Mosteiro de São Bento, do qual saiu depois para o Recife. Esses centros estruturam os conhecimentos basilares do ensino jurídico no país, convertendo-se nos campos irradiadores da cultura humanística pátria por muito tempo.

Nesse período inicial, a matriz curricular adotada para os referidos cursos apresentavam uma composição extremamente conservadora e voltada aos interesses das elites dominantes, tendo em sua formação disciplinas alusivas ao Direito Natural, ao Direito Público, à Análise da Constituição do Império, Direito das Gentes, Diplomacia, Direito Público Eclesiástico, Direito Pátrio Civil e Criminal, Direito Mercantil e Marítimo, Economia Política, Teoria e Prática do Processo adotado pelas leis do Império. (RODRIGUES, 2005).

Assim, realizado, ainda que de forma breve, um resgate histórico acerca do surgimento dos cursos jurídicos, passa-se a abordar a forma como os referidos cursos são normatizados na atualidade, conforme se fará a seguir.

\section{Análise crítica da resolução no 9/2004}


Ao voltar o olhar à realidade, tem-se que a educação jurídica apresenta suas bases delimitadas pelas Diretrizes Curriculares Nacionais do Curso de Graduação em Direito, devidamente dispostas na Resolução CNE/CES no 9/2004.

A Resolução CNE/CES no 9/2004 é composta por 13 artigos, sistematizados de forma a tentar regulamentar os requisitos mínimos a serem observadas pelas instituições de ensino superior na estrutura curricular dos cursos de Direito.

De acordo com o art. 4ำ da referida resolução, os cursos de graduação em Direito deverão possibilitar a formação profissional que revele, pelo menos, as seguintes habilidades e competências:

I - leitura, compreensão e elaboração de textos, atos e documentos jurídicos ou normativos, com a devida utilização das normas técnico-jurídicas;

II - interpretação e aplicação do Direito;

III - pesquisa e utilização da legislação, da jurisprudência, da doutrina e de outras fontes do Direito;

IV - adequada atuação técnico-jurídica, em diferentes instâncias, administrativas ou judiciais, com a devida utilização de processos, atos e procedimentos;

V - correta utilização da terminologia jurídica ou da Ciência do Direito;

VI - utilização de raciocínio jurídico, de argumentação, de persuasão e de reflexão crítica;

VII - julgamento e tomada de decisões; e,

VIII - domínio de tecnologias e métodos para permanente compreensão e aplicação do Direito.

Objetivando alcançar esses ideais, o curso de graduação em Direito deve apresentar no bojo do seu currículo conteúdos que permitam uma formação fundamental, profissional e prática.

A formação fundamental consiste no desenvolvimento de atividades voltadas à construção de uma base teórica adequada para o aprendizado dos conteúdos jurídicos técnicos. Inserem-se neste eixo as disciplinas propedêuticas, que são: Antropologia, Ciência Política, Economia, Ética, Filosofia, História, Psicologia e Sociologia.

O segundo eixo, o de formação profissional, tem como foco 0 desenvolvimento de conteúdos e práticas de caráter dogmático, buscando por meio de um conjunto de disciplinas teóricas capacitar o profissional para atuar nas diversas carreiras que esta área da ciência contempla. Aqui estão inseridas disciplinas como Direito Constitucional, Direito Administrativo, Direito Tributário, 
Direito Penal, Direito Civil, Direito Empresarial, Direito do Trabalho, Direito Internacional e Direito Processual.

O terceiro e último eixo é o de formação prática, cuja missão primordial é permitir que o aluno do curso de Direito consiga integrar teoria e prática incluindo-se aqui atividades relacionadas com 0 Estágio Curricular Supervisionado, com o Trabalho de Curso além das Atividades Complementares.

Outro ponto de grande relevância dentro da temática em comento é o que se encontra disposto no artigo 11 da Resolução em análise, o qual expressa que "a duração e carga horária dos cursos de graduação serão estabelecidas em Resolução da Câmara de Educação Superior."

Nesse segmento de ideias e nessa sequência normativa, tem-se a Resolução $n^{\circ}$ 2/2007, que traz um mínimo de 3.700 horas para a integralização do curso de Direito, ressaltando também que o limite mínimo para a conclusão da graduação deve se dá no período de 05 (cinco) anos.

No que concerne à articulação entre ensino pesquisa e extensão, constata-se que isso se encontra posto de forma muito tímida na Resolução, por meio do esboçado nos artigos $7^{\circ}$, 8ำ e 10, em que se abordam as exigências do estágio supervisionado, das atividades complementares e do trabalho de curso.

Não é demais transcrever os artigos supracitados, a fim de tornar mais clara a interpretação acerca do que se discute no presente estudo.

Assim, pelo preconizado no artigo 7울

o Estágio Supervisionado é componente curricular obrigatório, indispensável à consolidação dos desempenhos profissionais desejados, inerentes ao perfil do formando, devendo cada instituição, por seus colegiados próprios, aprovar o correspondente regulamento, com suas diferentes modalidades de operacionalização.

Já em relação às atividades complementares, fica estabelecido no artigo 8 que as mesmas

são componentes curriculares enriquecedores e complementadores do perfil do formando, possibilitam o reconhecimento, por avaliação de habilidades, conhecimento e competência do aluno, inclusive adquirida fora do ambiente acadêmico, incluindo a prática de estudos e atividades independentes, transversais, opcionais, de interdisciplinaridade, especialmente nas relações com o mercado do trabalho e com as ações de extensão junto à comunidade. 
Para a pesquisa, a previsão que existe é a contida no artigo 10, que enuncia ser "o Trabalho de Curso componente curricular obrigatório, desenvolvido individualmente, com conteúdo a ser fixado pelas Instituições de Educação Superior em função de seus Projetos Pedagógicos".

Assim, visualiza-se a necessidade de um maior alargamento do que se tem atualmente em termos de diretrizes, buscando ampliar os horizontes da formação do profissional do Direito em todas as dimensões enfatizadas até o momento.

Constata-se, no que diz respeito aos eixos de formação, a presença ainda muito rígida e formal de um número bem mais significativo de disciplinas meramente tecnicistas em detrimento das disciplinas de formação humanística, que aparecem em proporção ínfima e, na realidade prática, ficam resumidas a aulas teóricas ministradas nos dois períodos iniciais dos cursos, o que, sem dúvida, torna a formação limitada, não proporcionando o desenvolvimento pleno de cidadãos que possam ser não apenas meros aplicadores da lei, mas, acima de tudo, pessoas com consciência ética e humana, capazes de intervir com competência e sensibilidade em um cenário social marcado por traços de violência e exclusão que se tornam muitas vezes legitimadas pelo próprio aparato estatal.

Também no tocante ao trinômio que deve existir de forma indissociável entre ensino, pesquisa e extensão, percebe-se que muito tem o que se avançar nesse contexto, pois as diretrizes curriculares, ora trabalhadas, limitam-se a estabelecer o mínimo do mínimo para questões que, na prática, quando se busca uma formação integral, merecem ser vistas e executadas em sua máxima amplitude.

É inconcebível pensar em profissionais do Direito que não tenham uma formação que ultrapasse, de forma concreta, os limites da sala de aula, que não se debruçam sobre os horizontes da pesquisa científica e da extensão universitária durante sua trajetória acadêmica.

Sem esses pilares muito bem sedimentados, haverá um aumento do que há algum tempo vem se chamando de "crise no ensino jurídico" (ADEODATO, 1999; MURARO, 2010), crise esta que repercute de forma inevitável nas respostas oriundas daqueles que estão atuando no cenário jurídico atual de modo decisivo, cometendo, muitas vezes, arbitrariedades legitimadas pelo cargo que ocupa e por uma legislação cheia de entrelinhas que ampara atos pouco honrados, se vistos por um prisma ético e não meramente jurídico.

Assim, lançadas as ideias iniciais a respeito das diretrizes curriculares que norteiam os cursos de Direito atualmente, na quais se buscou nesse aspecto extrair os parâmetros existentes na seara da educação jurídica brasileira, passar-se-á a analisar a proposta de alteração das diretrizes curriculares que se encontra sendo elaborada, a fim de observar as principais mudanças nesse campo, refletindo se haverá e, em havendo, até que ponto os benefícios serão 
significativos ao contexto educacional em evidência.

\section{Propostas de alteração em curso para as diretrizes curriculares: para onde seguir?}

Sabe-se que cada momento histórico-social gera influência nos modelos de matrizes curriculares propostas/impostas aos cursos jurídicos.

Geralmente, a justificativa para apresentação de "mudanças" nas regras legais que sedimentam os currículos trazem à cena uma série de argumentos que buscam "camuflar" os reais impactos que o ensino poderá vir a sofrer por meio das inovações.

Assim, é necessário mergulhar com profundidade na temática, buscando fazer análises interpretativas do que está por trás dos discursos oficiais, ou seja, buscar o que na Hermenêutica Jurídica se costuma chamar de "mens legis' e "mens legislatoris", para podermos ter uma visão real acerca do que é apresentado para os cursos de Direito no Brasil, já em um futuro bem próximo.

De acordo com o que preceitua Moreira (1999, p. 8), ao abordar a teoria crítica do currículo sob o prisma sociológico,

o currículo é considerado um artefato social e cultural. Isso significa que ele é colocado na moldura mais ampla de suas determinações sociais, de sua história, de sua produção contextual. O currículo não é um elemento inocente e neutro de transmissão desinteressada do conhecimento social. O currículo está implicado em relações de poder, o currículo transmite visões sociais particulares e interessadas, o currículo produz identidades individuais e sociais particulares. O currículo não é um elemento transcendente e atemporal - ele tem uma história, vinculada a formas específicas e contingentes de organização da sociedade e da educação.

Assim, com base nessa linha de raciocínio e sabendo que todos os envolvidos com as temáticas relacionadas à educação jurídica estão cientes de que o Conselho Nacional de Educação vem buscando efetivar mudanças nas Diretrizes Curriculares Nacionais do curso de Direito, já se encontrando redigida proposta escrita das novas Diretrizes composta de 15 artigos, impõe-se fulcral a delicada tarefa de analisar as alterações mais substanciais propugnadas pelo Ministério da Educação, conforme se passará a fazer sequencialmente.

A primeira alteração relevante existente na proposta consiste na inclusão de "atividades extraclasse", que já levanta (ou já provoca) uma primeira indagação fundamental, qual seja: qual o real significado, em termos de incremento pedagógico, dessas atividades "extraclasse" mencionadas na proposta? 
Tal expressão, que sabemos ser advinda do ensino fundamental, apesar de aparentar ter uma definição esboçada no parágrafo terceiro do artigo $2^{\circ}$ da Resolução, gera uma série de dúvidas do que se busca atingir por meio das referidas atividades de forma concreta, não demonstrando o valor dessa "inovação".

Além disso, o referido dispositivo ao disciplinar que "para os cursos presenciais, a carga horária das atividades extraclasse é constituída por efetivo trabalho escolar..." deixa mais uma inquietação, qual seja: será possível a oferta de cursos de Direito não presenciais?

Também houve mudança nas nomenclaturas dos eixos de formação. 0 eixo de formação fundamental passa, pela proposta, a ser designado como eixo de formação geral, havendo a inclusão de História do Direito como disciplina obrigatória; o eixo de formação profissional passa a ser chamado de eixo de formação técnico-jurídica com a inserção das disciplinas de Direito Eleitoral, Ambiental, Previdenciário, Propriedade Intelectual, Tecnologias da Informação e Comunicação, Tutela dos Direitos e Interesses Difusos, Coletivos, Individuais e Homogêneos, com ênfase na solução consensual de conflitos.

Já o eixo de formação prática é nominado na Resolução como eixo prático-profissional, sendo a principal mudança nesse aspecto a presença de atividades sob a forma de "Tópicos Especiais" que buscam "articular novas competências e saberes necessários a novos desafios que se apresentam ao mundo do Direito".

Entretanto, maior preocupação reside no que está disposto no parágrafo primeiro do artigo $7^{\circ}$, que estabelece poder ser o estágio supervisionado:

Realizado na própria instituição através do NPJ, que deverá estar estruturado e operacionalizado de acordo com regulamentação própria aprovada pelo conselho competente, podendo, em parte, contemplar convênios com entidades ou instituições e escritórios de advocacia; serviços de assistência judiciária implantados na instituição; órgãos do Poder Judiciário, do Ministério Público e da Defensoria pública ou, ainda, em departamentos jurídicos oficiais importando, em qualquer caso, na supervisão das atividades e na elaboração de relatórios que deverão ser encaminhados à Coordenação de Estágio das IES, para avaliação pertinente. (Grifos Nossos).

Vale salientar que o artigo acima transcrito já foi, em sua totalidade, homologado pelo Ministro da Educação, já havendo inclusive a publicação do ato no Diário Oficial da União do dia 05 de julho de 2017.

O que se pensar: será a minimização ou o fim dos Núcleos de Práticas Jurídicas nos cursos de Direito? Em que lógica se insere uma mudança dessa 
magnitude? Qualidade do ensino é a palavra de ordem nesse cenário?

Outro ponto "inovativo" de relevância complexa vislumbrado na Resolução e que se traz à cena no presente trabalho é a possibilidade de redução do tempo de integralização da graduação em Direito, uma vez que o parágrafo único do artigo 11 faculta aos cursos de Direito em "turno integral a integralização mínima em quatro anos, desde que o PPC justifique sua adequação sem perda de carga horária estabelecida em lei".

Aqui, chega-se ao elemento mais "instigante" dessas observações, ou seja, ao ápice de preocupação do que está proposto para o futuro da educação jurídica brasileira.

Há na Resolução maiores detalhes de como se dará a dinâmica dos cursos de Direito em 'turno integral'? Não! Há referência na Resolução de que esse ponto seja objeto de norma específica? Não! Quais serão as razões para tantos vazios, para tantas dubiedades na Resolução por nós observada?

Assim, impossível não vir à mente, ainda que de forma hipotética, o que inicialmente se indagou a respeito da ideia de "atividade extraclasse".

Isso é realmente algo a ser refletido com responsabilidade, porque dessa forma, seguindo a lógica desta resolução, qualquer faculdade poderá se nominar como de "turno integral".

Por que não se cogitar, ainda, que isso pode representar uma forma discreta de se iniciar o Ensino a Distância nas graduações como atividade extraclasse, já que a Resolução não faz qualquer proibição nesse sentido?

Cumpre registrar também que o artigo 12 da Resolução analisada disciplina que "o curso de graduação terá (no mínimo) até $20 \%$ de sua carga horária destinada às atividades complementares e ao estágio supervisionado". Já no artigo 13 há uma simples ressalva no tocante ao estágio curricular obrigatório, ao dispor que o mesmo compreenderá "no mínimo 12\% da carga horária total do curso".

Ou seja, a perspicácia da norma está na expressão "até", que faz com que qualquer percentual nessa margem, seja esse percentual com pelo menos $12 \%$ da carga horária total do curso, no caso do estágio curricular obrigatório, seja condizente com os padrões de qualidade emanados de quem tem o poder de regulamentar a educação no país. O que isso traduz: a precarização do estágio supervisionado e/ou das atividades complementares?

Certamente, diante da mercantilização do ensino vivenciada na atualidade, a diminuição da carga horária destinada a tais atividades será inevitável, já que representa, acima de tudo, corte em gastos e aumento de lucros.

Não é demais lembrar que "o processo de reestruturação global do Estado e os novos ditames da economia de mercado provocaram impactos nas diferentes esferas sociais e, como não podia deixar de ser, determinaram 
importantes reformas na esfera educacional". (PRADO; DIÓGENES, 2011, p. 86).

Assim, para as instituições que não prezam pela qualidade do trabalho desempenhado, que entendem educação como um segmento comercial e se limitam a emitir diplomas, essa prática, sem dúvida, será uma constante, colocando-se em risco a formação dos futuros profissionais do Direito e, consequentemente, a sociedade como vertente mais ampla.

Dessa forma, após todas as observações realizadas a respeito da proposta das novas Diretrizes Curriculares Nacionais do curso de Direito, oriunda da Câmara de Educação Superior do Conselho Nacional de Educação, chega-se ao final deste trabalho, lançando não só questionamentos, mas também levantando inquietações e reflexões.

Não se torna excessivo delinear aqui, dentro das ideias defendidas, o que ensina Frigotto (2003, p. 31), ao abordar as práticas educativas no modelo neoliberal, enfatizando que:

A qualificação humana diz respeito ao desenvolvimento de condições físicas, mentais, afetivas, estéticas e lúdicas do ser humano (condições omnilaterais) capazes de ampliar a capacidade de trabalho na produção de valores de uso em geral como condição de satisfação das múltiplas necessidades do ser humano no seu devenir histórico. Está, pois, no plano dos direitos que não podem ser mercantilizados e, quando isso ocorre, agride-se elementarmente a própria condição humana.

Com tais reflexões, intenciona-se ter dado um passo inicial que venha servir de alicerce para que estudos mais densos se desenvolvam a respeito da temática e, principalmente, para que as incoerências constatadas nas Resoluções em discussão possam ser corrigidas ou mesmo reformuladas na intensidade que se fazem necessárias.

Reduzir o tempo da integralização do curso, criar "formas alternativas de avaliação", flexibilizar as atividades do Estágio Supervisionado "em função da própria capacidade do aluno", permitir uma carga ínfima destinada às atividades de Estágio Supervisionado e Atividades Complementares, são algumas formas estratégicas de se privilegiar as instituições que se preocupam basicamente em ganhar um número maior de estudantes em detrimento do verdadeiro sentido de educar.

Visualiza-se a proposta de resolução, da forma que está posta e redigida, como uma verdadeira afronta para a qualidade da educação jurídica brasileira, o que faz recordar as palavras de Mészáros (2008) quando o autor indaga:

A grande questão é: o que aprendemos de uma forma ou de outra? Será que a aprendizagem conduz à autorrealização dos 
indivíduos como "indivíduos socialmente ricos" humanamente, ou está ela a serviço da perpetuação consciente ou não, da ordem social alienante e definitivamente incontrolável do capital? (p. 47).

Há algum tempo a sociedade vem assistindo de forma pouco positiva a grande expansão dos cursos jurídicos. Como afirma Nascimento,

a expansão dos cursos jurídicos no Brasil, com uma concentração maciça no setor privado, passou por uma política adotada na década de 90, passando a conter uma participação maior da iniciativa privada no setor educacional, descentralizando, assim, a concentração do ensino em instituições públicas para a esfera privada. (2016, p. 35).

Prosseguindo no raciocínio, Feitosa (2007), mostra que a educação superior foi "empresariada", havendo a nítida privatização desse segmento como consequência da reforma neoliberal promovida pelo governo.

Endossando tal segmento de ideias, o Conselho Federal da OAB sempre se posicionou de forma contrária à proliferação desordenada de cursos de Direito, envidando esforços para o surgimento de critérios avaliativos mais rígidos nos processos de autorização, reconhecimento e renovação de reconhecimento de cursos, assim como tentando por anos que o parecer emanado da $O A B$, nesses processos avaliativos, apresentasse natureza vinculativa e não fosse somente de caráter opinativo.

Entretanto, na contramão dos anseios da OAB e de boa parte da sociedade, surge a proposta objeto de análise deste artigo que, parece querer flexibilizar a educação jurídica brasileira o que certamente trará um futuro sombrio para essa seara.

Explicações para esse fenômeno "flexibilizador", além das considerações já declinadas ao longo deste trabalho, seriam talvez prematuras. Mas, não se pode deslembrar que, nos dias atuais, o curso de Direito já começa a mostrar taxa de ociosidade de vagas considerável em todo o país, seja porque grande parte da demanda que estava contida já foi absorvida, seja porque o grau de dificuldade para a conclusão desta graduação apresenta-se como um fator que muitas vezes afasta um contingente de estudantes que almejam a graduação.

$E$, não é à toa que muitos grupos educacionais assistem com aflição essa nova realidade, eis que o curso de Direito sempre representou um excelente suporte financeiro para todas as IES.

Assim, resta declinar o entendimento de que facilitar as "regras do jogo", infelizmente, pode ser uma importante estratégia para aqueles que querem salas de aulas cheias, receitas monetárias altas, domínio de mercado absoluto, mas 
que pouco se interessam com a qualidade do ensino em si.

\section{Inconclusões}

Mesmo com o passar do tempo, os cursos de Direito continuaram (e continuam) a reproduzir valores referentes aos interesses das classes sociais dominantes. Com a delimitação das atuais diretrizes curriculares dos cursos jurídicos na Resolução CNE/CES nำ 9/2004, que conseguiu superar vários entraves históricos nos cursos jurídicos, ainda hoje os interesses de mercado se sobrepõem às reais necessidades e à melhoria da qualidade do ensino jurídico.

Quando se observa de maneira cuidadosa o teor da referida resolução, verifica-se que de várias maneiras ela tenta trazer ao curso de Direito um conjunto de valores importantíssimos a uma formação calcada em valores humanísticos. Isto se torna evidente na medida em que em seu texto a formação do jurista deve se dar a partir de três eixos de formação: a fundamental, que busca construir uma base teórica que melhore a formação técnica do jurista; a profissional, que objetiva construir um conhecimento de cunho dogmático, ou seja, a operacionalização do discente para a atuar na esfera jurídica; e prática, permitindo a completa integração dos saberes vivenciados em sala de aula com a realidade.

Uma crítica que precisa ser feita neste sentido é a presença mais acentuada das disciplinas tecnicistas em detrimento das disciplinas de formação humanística, algo que poderia ser mudado com a proposta para as novas diretrizes curriculares do curso de Direito, pois essas disciplinas de caráter propedêutico acabam se resumindo aos dois períodos iniciais do curso, o que é insuficiente a uma formação que amplie os horizontes do futuro jurista.

Além disso, a resolução fala de algo essencial ao ensino jurídico, que é a articulação entre ensino, pesquisa e extensão. Dentro de um contexto em que ainda hoje prevalece um apego demasiado ao dogmatismo e a um modelo de ensino jurídico ultrapassado, relacionar ensino às outras esferas do conhecimento se torna primordial à evolução do ensino jurídico.

Mesmo diante das carências evidenciadas da análise da resolução, a tendência percebida com a nova proposta de diretrizes curriculares para o curso de Direito é de flexibilização da matriz curricular, algo realmente assustador para um contexto em que o ensino jurídico se encontra precarizado. Vários dos dispositivos trazidos no projeto deixam uma grande dubiedade em sua interpretação, permitindo amplas especulações sobre a futura estrutura e organização dos cursos jurídicos.

Uma das maiores preocupações inerentes à interpretação da proposta se encontra na expressão "para os cursos presenciais", que denotaria a possibilidade de cursos não presenciais de Direito. Isto porque se trata de um curso que possui um viés teórico-prático muito grande, o que leva a 
questionamentos sobre a viabilidade de cursos não presenciais na categoria.

Outra grande preocupação se encontra no eixo prático-profissional, que traria uma mudança significativa a atual estrutura e formatação dos cursos de Direito: a possibilidade de se realizar o estágio obrigatório em outros lugares, através de convênios variados dentro da esfera jurídica. Em outras palavras, a proposta evidencia a dispensabilidade dos Núcleos de Prática Jurídica dentro das instituições de ensino superior em Direito, algo que de fato afastaria muito o discente de um necessário aprofundamento prático.

Algo que também chama a atenção na proposta é a presença do "turno integral e a integralização mínima em quatro anos", considerando-se que não haja "perda da carga horária". Gera-se, com tal dispositivo, grande preocupação, pois sua redação gera muitas dúvidas. Como seria realizado o ensino do Direito em um turno integral? Que critérios seriam utilizados para garantir a adequada integralização do curso? Enfim, percebe-se que tal norma poderia causar muitos prejuízos à qualidade do ensino jurídico a depender da interpretação que lhe seja dada pelas instituições de ensino superior, principalmente se esse ensino integral se der através das "atividades extraclasse" mencionadas na resolução (de forma igualmente insuficiente, diga-se).

Estas são algumas das inquietações evidenciadas da análise da resolução. Muitas outras poderiam ser reiteradas neste momento para destacar o grau de precarização que o ensino jurídico pode experimentar nos próximos anos com a aprovação das novas diretrizes.

Vem à superfície a discussão da mercantilização desenfreada dos cursos jurídicos neste ponto. As medidas mencionadas favorecem aos grandes grupos empresariais que buscam tão somente aumentar suas margens de lucro em detrimento do ensino superior brasileiro. Esta é a dura e cruel realidade do ensino jurídico: a redução do tempo de integralização, a flexibilização do estágio supervisionado, a forma como o ensino integral foi colocada na proposta denotam um futuro incerto para a qualidade do ensino jurídico.

Se a atual resolução vigente já deixa muito a desejar em termos de concretização do perfil humanístico, reflexivo e crítico desejado ao jurista, imagine-se com a proposta ora avaliada, que em nenhum ponto busca sanar as deficiências de fato experimentadas atualmente, mas, ao contrário, apenas aumenta o fosso entre qualidade do ensino e Direito.

Portanto, é preciso refletir sobre os rumos do ensino jurídico. As falhas históricas e culturais que permeiam suas bases, ainda hoje, nunca foram devidamente sanadas, mas, mesmo assim, tem-se uma proposta que pode precarizar, ainda mais, o ensino do Direito no país, o que vai na contramão dos anseios sociais.

\section{Referências}

ADEODATO, J. M. L.. Bases para uma metodologia da pesquisa em Direito. Revista CEJ. Brasília, DF, v. 7, n. 1, p. 143-150, 1999. 
BAETA, Herman Assis. História da Ordem dos Advogados do Brasil. Brasília: OABEd, 2003, Vol. 1.

BASTOS, A. W. Os cursos jurídicos e as Elites Políticas Brasileiras: ensaio sobre a criação dos cursos jurídicos. Brasília: Câmara dos Deputados,1978.

BRASIL. Ministério da Educação e Cultura. LDB - Lei no9394/96, de 20 de dezembro de 1996. Estabelece as diretrizes e bases da Educação Nacional. Brasília: MEC, 1996.

BRASIL. Ministério da Educação e Cultura.Decretono 5.773/2006, de 09 de maio de 2006. Dispões sobre o exercício das funções de regulação, supervisão e avaliação de instituições de educação superior e cursos superiores de graduação e sequenciais no sistema federal de ensino. Brasília: MEC, 2006.

BRASIL. Ministério da Educação e Cultura. Resolução no 09/2004, de 29 de setembro de 2004. Institui as Diretrizes Curriculares Nacionais do Curso de graduação em direito e dá outras providências. Brasília: MEC, 2004.

BRASIL. Ministério da Educação e Cultura. Resolução no 02/2007, de 18 de junho de 2007. Dispõe sobre a carga horária mínima e procedimentos relativos à integralização e duração dos cursos de graduação, bacharelados, na modalidade presencial. Brasília: MEC, 2007.

FAGUNDES, Paulo Roney Ávila. OAB ensino jurídico: o futuro da universidade e os cursos de direito - novos caminhos para a formação profissional. Brasil: $O A B$, 2006.

FEITOSA NETO, Inácio José. O ensino jurídico brasileiro: uma análise dos discursos do MEC e da OAB. Recife: Ed. do autor, 2007.

FRIGOTTO, Gaudêncio. Educação e a crise do capitalismo real. São Paulo: Cortez, 2003.

LÔBO, Paulo Luiz Neto. OAB ensino jurídico: parâmetros para elevação da qualidade e avaliação. Brasília: OAB, 1996.

MÉSZÁROS, István. A educação para além do capital. São Paulo: Boitempo, 2008.

MOREIRA, Antônio Flávio Barbosa; SILVA, Tomaz Tadeu. Currículo, Cultura e Sociedade. São Paulo: Cortez, 1999.

MURARO, C. C. A formação do professor de direito. Revista Âmbito Jurídico. Rio Grande, RS, v. 13, n. 73, fev. 2010.

NASCIMENTO, Tarcizo Roberto do. O marco regulatório da educação jurídica brasileira e a redefinição do papel do interventor. Brasília: Tipográfica. 2016.

PALMEIRA, Lana Lisiêr de Lima. $O$ ensino jurídico em Alagoas: razões e sentidos de sua constante valorização.Maceió: EDUFAL. 2011.

PRADO, Edna Cristina do; DIÓGENES, Elione Maria Nogueira (Orgs). Avaliação de políticas públicas: interface entre educação \& gestão escolar. Maceió: Edufal, 2011.

RODRIGUES, Horácio Wanderlei. Pensando o ensino do direito no século XXI. Florianópolis: Fundação Boiteux, 2002.

VENÂNCIO FILHO, A. Das Arcadas Ao Bacharelismo. 2.ed. São Paulo: Perspectiva, 1982. 